\title{
A NUMERICAL MODEL TO ASSESS THE ROLE OF CRACK-TIP HYDROSTATIC STRESS AND PLASTIC DEFORMATION IN ENVIRONMENTAL ASSISTED FATIGUE CRACKING
}

Sergio Baragetti, Department of Management, Information and Production Engineering, and GITT- Centre on Innovation Management and Technology Transfer, University of Bergamo sergio.baragetti@unibg.it

Dan Kujawski, Mechanical and Aeronautical Engineering, Western Michigan University

Francesco Villa, Department of Management, Information and Production Engineering, University of Bergamo

Key Words: $\quad$ Hydrostatic stress, Hydrogen Embrittlement, Environmentally Assisted Cracking, Fatigue, Finite Element Mode

To better understand the mechanics of environmentally assisted cracking, and particularly hydrogen embrittlement, a correct description of the hydrostatic stress field is indispensable. The concentration of hydrogen in the proximity of the crack tip is indeed dependent of the hydrostatic stress effect on the microstructural lattice of the material. The overall parameters of the hydrostatic stress, including peak value, its location, gradient and distribution size are fundamental to assess the effect on hydrogen distribution near the crack tip. $\mathrm{H}$ concentration show indeed an exponential dependence on hydrostatic stress, so that even a moderate increase in the applied stress is traduced in a dramatic rise of hydrogen concentration. In order to investigate the mechanism beneath hydrogen embrittlement, a proper modelling of the hydrostatic stress is mandatory. Moreover, strain hardening might significantly interfere with the actual stress distribution, thus becoming a relevant parameter. The stress and strain field is also deeply affected by the presence of sharp notches. In the present work, a detailed Finite Element model, based on actual fatigue testing of notched Ti-6Al$4 \mathrm{~V}$ specimens is proposed, providing a deeply informative tool to assess the hydrostatic stress and the plastic strain in the proximity of the crack tip. The data from the model are compared to available results and experiences in literature.

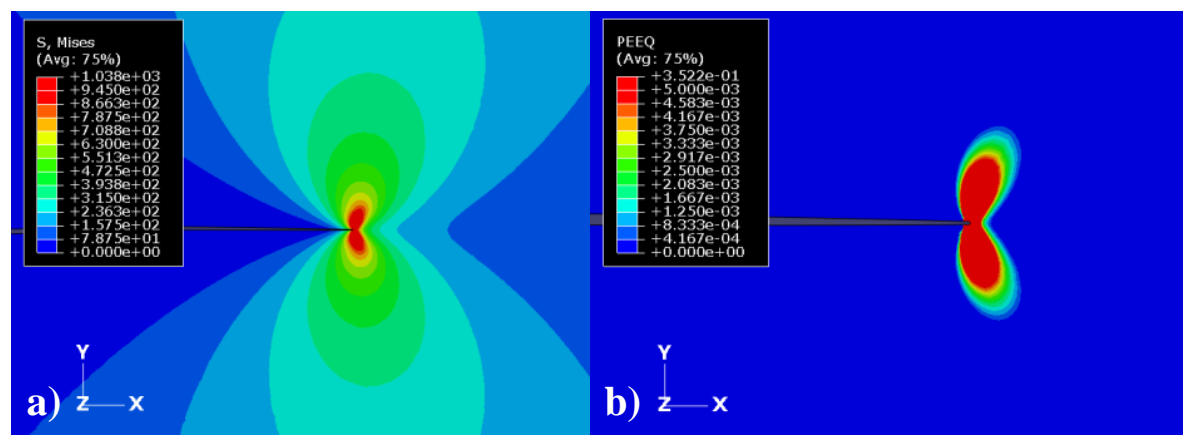

Figure 1 - FE simulation results: (a) von Mises Stress and (b) Equivalent Plastic Strain at the crack tip.

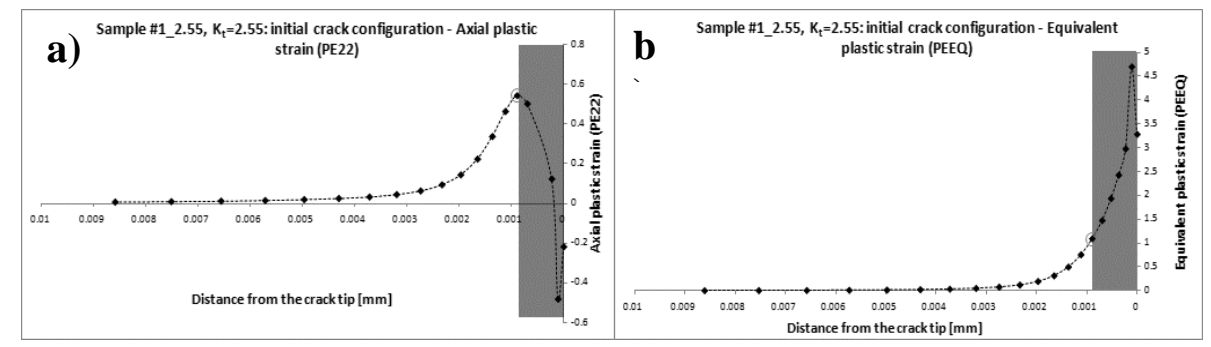

Fig. 2: Axial strain in the proximity of the crack tip for $K t=2.55$ : (a) axial plastic strain and (b) equivalent plastic strain. 